\title{
SDO

\section{Towards Transdisciplinary Urbanism: Megaprojects, Power and the Urban Imagination}

\author{
Gerardo del Cerro Santamaría, U.S. Fulbright Senior Specialist in Urban Planning, New York Invited Professor of \\ Urbanism and Globalization School of Architecture and Urban Planning Shenyang Jianzhu University Shenyang, Liaoning, \\ China, Email:gdelcerro@gmail.com \\ Received 17 June 2018; Accepted 8 July, 2018 \\ Copyright (C) 2018 Gerardo del Cerro Santamaría. This is an open access article distributed under the Creative Commons \\ Attribution License (https://creativecommons.org/licenses/by/4.0/), which permits unrestricted use, distribution, and \\ reproduction in any medium, provided the original work is properly cited.
}

Available online 11 July, 2018 at www.atlas-journal.org, doi: 10.22545/2018/0099

\section{T}

his article presents some building blocks for a transdisciplinary approach to the study of urbanism. By using the case of urban megaprojects research as an example of potential transdisciplinarity, the article explores concepts such as "centrality" and "bordering" in order to suggest distinct and yet interrelated ways to explain "power" and "growth" in a terrain - that of urban studies - subject to several disciplinary accounts that are typically not integrated. In opposition to the economic logic of urban megaprojects, it is suggested a particular idea of an "urban imagination" that contributes to establishing the transition to a more systematic and integrated undersanding of megaprojects and urbanism under a transdisciplinary vision. It is suggested that a transdisciplinary approach to urbanism as a methodology ought to take seriously the ethical ideal of inclusiveness, which fails to realize when we hold the belief that the outside world of things is not as deserving as the inner world of the mind, and when we privilege the perspective of epistemology over ontology, over the conscience of the eye and over the value of observations. When we build a transdisciplinary approach to urbanism, a key issue then is how to revive the "reality of the outside" both as a dimension of human experience and as a research strategy.

Keywords: Transurbanism, power, megaprojects, urban imagination, discovery, design.

\section{Introduction: Is Urbanism a Transdiscipline?}

Urban research has always thrived at the intersection of multiple disciplines. According to Anthony Townsend, in the early days of urban planning in the late 19th century, urban planning emerged from interactions amongst experts in civil engineering and architecture, medicine and public health, sociology and (like Patrick Geddes) occasionally biology. In the 1960s, many urban research programs re-organized themselves under the rubric of urban 
studies drawing even more broadly on social sciences from economics, geography, history, political science and sociology.

Perhaps, even if only in their sheer numbers, the most significant new arrival to the urban research community are the physicists, who have not traditionally engaged in the study of cities in any substantial form. These scientists, who have tackled some of our most challenging scientific problems, are bringing their experience, powerful new theories and analytical tools to bear on the complexity of urbanization. Geoffrey West and Luis Bettencourt, who have pioneered research on urban scaling at the Santa Fe Institute, spent the earlier part of their careers at Los Alamos National Laboratory. At Harvard University, 20-year old astrophysics prodigy Henry Lin and department chair Abraham Loeb mathematically derived Zipf's Law, which explains why there are more small cities than large ones - by applying techniques used to explain the size distribution [1].

Townsend explains that urban researchers like to think they work on very large scales, but their ambitions are humbled by galaxy-watchers; they also purport to pay attention to detail, and the nuances of place. But other physical scientists are probing new ground in the structure of the very small urban world. For instance, researchers at MIT's Concrete Sustainability Hub describe cities using the mathematics of crystals. By noting that conventional approaches to measuring urban heat island effects rely on a single population or building density variable, they point out " $[\mathrm{T}]$ he striking resemblance between urban environments and molecular structure of materials", which 'allows us to leverage common methods from statistical physics to reduce the complexity of urban systems to a universal set of dimensionless measures". Some cities mimic crystals, they find, with "distinct periodic Geometries" (Chicago and New York) - others mimic liquids (Boston and Los Angeles) with "more sporadic and chaotic distributions" of stars in galaxies [2].

While they have not advanced as aggressively as physical scientists, the biological scientists are beginning to engage cities as sustainability surges to the forefront of policy and planning agendas, elevating their importance. For instance, the head of ETH's Future Cities Lab in Singapore - arguably the largest urban science center by far - is a plant ecologist who started his career in a rainforest! Peter Edwards was the dean of environmental sciences at ETH and saw the lab as an opportunity to advance the agenda he had helped craft as coordinator of the Alliance for Global Sustainability over many years previously.

While physical scientists may bring new ideas that transform our thinking about the city at both the very large and the very small scale, it may be in the biological realm that the best new notions about the human scale lie. As Edwards explains:

The thing I know about rainforests is they are sustainable and they are highly decentralized they have multiple redundancy systems in them. Thats exactly the kind of industrial system we need... moving from a zoned sort of city, which depend on large centralized services... to a highly decentralized system with much more interconnection between the individual buildings so that they function together to regulate the urban environment in a way that is not done at present [3].

To envision a smart city infrastructure in the form of a rainforest canopy requires, well, a rainforest scientist. Engaging with biology may also carry other unanticipated benefits - the field has been overrun in recent decades by physicists and computer scientists, spawning the sub disciplines of biophysics and bioinformatics, but without disassembling itself entirely. As a field encountering powerful and disruptive new ideas from the outside, biology - long seen as 'soft' itself - may be a model of intellectual resilience for urbanists to learn from.

Finally, Townsend reports that the great strides being made in mapping the human brain are informing every aspect of urban research, with often very practical applications for urban professionals. One project at the University of Waterloo uses advanced brain scanning techniques to measure how people perceive and navigate complex urban environments. Participants are placed into highly immersive simulations of city spaces using sophisticated head-mounted displays and precise motion tracking. They are able to walk freely through photo-realistic simulations of urban spaces that are replete with depth, colour, and motion. We can monitor their gaze and their movements along with their physiology using a set of unobtrusive sensors while they do so. Such studies "give us a set of powerful methods by which to predict the psychological effects of an urban design before anything is built" [4]. 
In sum, urbanism is akin to a transdisciplinary approach where not only physicists and biologists can make contributions, but also - and perhaps more obviously - designers and architects, social scientists and philosophers. In the next section I will use a specific example in urban research, that of urban megaprojects, to show how notions of power, bordering and growth can be tackled from a transdisciplinary perspective, thus illuminating a particular urban imagination, that of the reality of the outside versus the life of the mind. Transurbanism would then become discovery and creation through observation, knowledge and design of the outside.

\section{Urban Megaprojects}

Megaprojects are embraced and advocated by urban elites as pro-growth strategies. This view is contested, as they may be less important than developments at the grassroots level that act as catalysts of economic improvement. The study of UMPs helps us understand the dynamics of capitalism and urban development at various spatial and geographical scales. UMPs are also a convenient empirical arrangement to observe how sustainability and sustainable governance work in specific urban settings. While globalization may explain why policy discourses favor UMP construction, it does not provide an explanation of the specific causal mechanisms through which this form of urban redevelopment seems to be the prime choice for revitalizing cities around the world.

We know that the privatization of planning, usually in the form of new "public-private partnerships", has had an important effect in the specific ways in which megaproject planning, design and construction have taken place. In an entrepreneurial urban context favored by globalizing forces, where public agencies cede control and delegate functions to private institutions and actors, there is a legitimate question from commentators about the meaning of public space. The agencies and administrative procedures that implement planning policy are embedded within the varying organizational structures of states. The structure of new public-private partnerships poses the question of how different the role of contemporary public agencies is from their predecessors.

Researching new forms of collaboration and confrontation between public and private actors and agencies may shed light into the prospects for public space in the city. Further, it would take into account the effects of globalization on privatized control of urban spaces by local and national authorities, and why it is happening in disparate socio-spatial and regional contexts almost simultaneously. Globalization is a contextual, rather than causal, force behind the proliferation of UMPs around the world. It is important to remember that the physical outcomes and impacts of UMPs are usually place-specific, albeit searching for commonalities across various developmental contexts is a legitimate social-scientific task.

Successful cases of redevelopment via megaprojects and iconic architecture, such as Bilbao, where the Abandoibarra/Guggenheim megaproject instantly put the city on the map, are not frequent. Policymakers ought to keep in mind that the "visibility" aimed at by UMP construction may not have a significant impact beyond a given locale. UMPs in second or third-tiered cities have limited chances of success outside of their specific locales, and the benefits realized through UMP construction and impacts tend to concentrate around local and regional business interests and the interests of the political elites, rather than benefiting the urban population at large, as Susan Fainstein has shown [5]. An important corollary of this is that the tangible impact of UMPs on the transformation of cities requires consideration of the socio-economic context in which they (both the megaprojects and the cities themselves) develop. With this in mind, this chapter seeks to shed light on both the contextual and structural forces framing, enabling and constraining megaproject-based sustainable urban redevelopment.

The concept of sustainability has evolved in the last few decades into a required aspect of urban and metropolitan-level public action, specifically design and practice of urban and land-use planning. Planning approaches such as New Urbanism, Smart Growth and Sustainable Cities have in turn become the leitmotiv of contemporary planning. As a parallel development, the planning and construction of Urban Megaprojects (UMPs) in both global and globalizing cities has come to epitomize the ambitions of urban elites and a main priority in the discussions about the chances of increased visibility for local economies and cultures in the global arena. While research on the UMPs phenomenon has grown steadily to the point of becoming an emergent discipline in its own right, little is known about the relationships between UMPs and urban sustainabil- 
ity. In particular, governance arrangements that foster urban sustainability require further research.

\section{Megaprojects Against the City}

\subsection{Historic Dimension}

As Florian Koch points out, in his study on the history of the European City Leonardo Benevolo describes the cities "as one of the reasons - maybe the most important - that Europe constituted itself as a historical unit" [6]. And he adds that the coexistence of public authorities and free market enterprise that have divided competences over land use issues characterizes the European cities. This equilibration between private rights and public control can only work if the interests of both parties are adequately represented [7]. The inherent conflict between a private and a public realm, but also the influence of different historical eras which shaped and still shape the urban development, leads to a so-called "presence of history" in European Cities which is still evident and visible in the daily life of the city dwellers. The European City is a place where a special form of living emerges which differentiates the inhabitants of urban areas from rural. However, a critical revision is necessary if the distinction between rural and urban lifestyles still exists today or rather if we experience a complete urbanization of society.

\subsection{Social Dimension}

The European City as a social formation is characterized through a minor grade of socio-spatial segregation, especially compared to cities in the Unites States, Koch rightly points out. At the same time the role of its citizens as important actors which shape everyday life in urban areas through their participation in organizations, associations, citizens groups is a characteristic of the European city. Therefore the ideal type of European city can be described as a "collective actor". Its urban development and urban politics are not only determined by the elected politicians and other public authorities but through a variety of different groups and micro-projects, the major part of them not having an institutionalized form.

\subsection{Political Dimension}

Koch further explains that the political dimension of the European City is a product of its embedding in the national welfare state and a far-reaching capacity to act within a stable national context. This capacity to act is based on the fact that cities and municipalities receive national funds and have the autonomy to determine up to a certain degree how these funds are used. Thus, cities can determine their politics and developments. In addition, the inclusion in the supranational system of the European Union strengthens the capacity to act because secondary to national funding, cities can also strive for European funds and use these for their development. Symbols for the municipal autonomy and the far-reaching capacity to act are local investments in infrastructure, water supply, public housing and urban planning: European Cities have (had) the legal competences and the possibility to create and implement a local welfare state and determine the course of their policy. Also in a similar way the creation of modern urban planning instruments during the 19th century in European cities can be understood as a demonstration of municipal autonomy and the political idea to restrain market forces and obtain a coordinated development on the local level.

\subsection{Urbanism/Urban Design Dimension}

The physical characteristics of the European City can be described as follows: a historical centre with low rise buildings (except for state and religious buildings), public places, neighborhoods with a mixed social structure and small commercial units, clear geographical limits, a high degree of densification and a well equipped public transport system. There is a mix of functions and a sensible treatment of historical buildings as attributes of the European City.

Public space, particularly the market place has a huge importance for being the location where urban society in medieval Europe was founded and different social groups met and interacted in a democratic way. The design of the public space and its use through different social groups therefore determines a major difference between the European City and the Latin American City: for example, one which was shaped from its Hispanic origins through different types of public spaces for different population groups and not as a democratic place. Regardless of the often 
romanticized notion of the European City as an open and democratic city, the urban structure of the European city can be characterized through density, compactness, centrality and mixed uses.

The contradiction that the spatial structure of European Cities also consists of extensive suburban areas, "Zwischenstadt/Cities in-between" and depopulated urban centers (and not only of dense and compact urban structure) shows that the European City Model is not a descriptive concept which mirrors real urban development processes but an ideal type.

The revision of the distinctive approaches in history, sociology, political sciences and urban design/urbanism reveals different definitions of the European City. The European City can be understood as the ideal type of a certain form of built-up environment, and as a social formation on the local level or as a political unit that poses a high degree of autonomy. Nevertheless interconnections exist between the various definitions that are the focus of the concluding chapter of this article.

This analysis by Koch may lead to the conclusion that the European city has to be interpreted as a "myth" which is not able to grasp new urban realities. If we see the European city as a normative model or as a kind of instruction manual it provides only limited answers to the new political, economical, social and ecological challenges that cities in Europe and in Non- European countries are facing today Thus a readjustment of the major contents of the model to the present urban development trends is necessary.

Nevertheless it has an academic relevance as a neo-weberian analytical framework that helps to categorize urban development in different cities and can be seen as an important counterbalance to universal urban theories. Even more important, the European City still has its importance and future not only in the academic realm but also in practical urban development: Not as a concrete instruction manual for urban development but rather as a possibility to join forces between disciplines. As Koch convincingly demonstrates, the model becomes irrelevant or even contradictory if the different dimensions are regarded independently. A city whose built-up environment is shaped by density, compactness and mixed-uses cannot be characterized as a European City if the social, cultural and political aspects are not corresponding. The interaction between disciplines can be seen as the strength of the model. The European City can be understood not as a precise model but as the idea to see urban development as a transdisciplinary holistic concept, which is nurtured by sociological, political, historical and urban planning aspects that provide an integrated view on the city. It allows the approximation of the complex reality in European and Non-European cities and is in this spirit more important than ever.

The point I want to make about urban megaprojects in connecton with transdisciplinarity is that megaprojects, which rupture the balance in the city by appropriating and shifting the meaning of density, compactness, centrality and mixed uses, needs to be subject to the holistic logic of urban development analysis as suggested by Koch and others, both from the viewpoint of knowledge discovery and from the perspective of design. I shall elaborate on this below.

\section{Megaprojects and Power}

For the purposes of this paper, I will approach the topic of urban megaprojects (from outside architecture, as I am a social scientist) by simply laying out some elements that would need to be included in an analysis of megaprojects when we take seriously the unavoidable and dialectical relationship between cities and the larger socio-economic context, between urbanism and globalization, and by the way this is not just simply saying local vs. global because this dychotomy is, in my view, just a shortcut to bad theory, and maybe later there will be a chance to say something about levels of analysis and spatial scales, a concept to which geographers have contributed a great deal, as you know.

Cities, and urban megaprojects, are expressions or reflections of the larger economy and society, as Manuel Castells and David Harvey taught us long ago [8], reflections or expressions of the global capitalist economy, with its uniformities, variations, and evolution across time and space, and I uttered these words twice because the terms imply a particular analytical approach, they are very loaded terms.

The particular analytical approach they imply means that in order to understand cities, and urban megaprojects, we must try to understand the workings of the capitalist economy, and, in turn, the way we understand this larger context has a direct effect on how we understand cities, and how we understand urban megaprojects as well. 
For the urban imagination, this precisely means that globalization at work can be identified in the concrete manifestations of city life, which is why the study of urbanism is so revealing to understand cities, of course, but most interestingly to understand the dynamics of capitalism. Cities and urbanism (I deliberately use both ideas on equal terms in times of planetary urbanization, we cannot do with just one of them) make capitalism and globalization and they are, in turn, made by them.

So as I see it there is a double feedback loop, mutually reinforcing, between the idea and the workings of "urbanism" and the idea and the workings of "capitalist globalization". And this analytical approach has remained central to my research efforts to date.

To me the question has been and still is - what do we see when we open up the zoom and observe urban megaprojects from the perspective of the larger socioeconomic context rather than adopting a close up look at megaprojects themselves with the global capitalist political economy in a more or less distant background? This question lies at the core of the book that my colleagues and I published a few years ago on "Urban Megaprojects. A Worldwide View" [9].

From this angle, I want to start by focusing on the ideas of "centrality" and "border," and I will make a few comments about how they express and reflect a certain conception and certain dimensions of power. As you know, power - and urban politics, the politics of regeneration, revitalization and growth is a fundamental concern for UMP researchers I'd say everywhere.

\subsection{Centrality and Visual Power}

Let me start with centrality, and centrality as visibility. Centrality can be characterized as the spatial equivalent of power, and when dealing with such an overloaded and abstract concept it makes a big difference how we interpret it and how we operationalize it. French philosopher Henri Lefebvre uses the ideas of "abstract and concrete space" to analyze "spatial power" [10] and, to add to the discussion, I want to say a few words about "visual power," and "iconicity" in particular, and this is not to make the so-called "critique of the lacking variable" to Lefebvre's analysis, but I think iconicity deserves to be mentioned because it has become a very important concept to understand the dynamics of urbanism and how places are made and transformed in times

\section{of globalization.}

I interpret "iconicity" for our purposes today as a tool for urban cities (usually urban elites) to gain visibility and therefore move up in the global hierarchies of centrality. becoming visible is becoming central in both the abstract and the concrete spaces of globalization, and centrality, from the perspective of the ideology of growth which marks urban fortunes in times of neoliberalism, is usually measured by accounting for flows and connections in the network of world cities. Iconic buildings and UMPs are usually an effective tool to achieve image change for a city, and we know that image change can bring many positive externalities. This is consistent with the findings by many researchers that UMPs can work as catalysts for growth but not so often as direct generators of urban growth.

The power of visual symbols through iconicity also plays a fundamental role in the worldwide deployment of contemporary globalization via umps as well as the creation of large-scale social spaces representing capitalisms transnational strategies because it has the power of shifting the significance of specific buildings and the cities where they are built. When the growth machine aims at overcoming the - usually very challenging - structural obstacles that prevent a city from becoming "global" or "globalizing", one of the tools of choice is the visual power of iconicity, conveniently marketized and broadcast in the mass media. Iconic buildings provide benefits that compensate for the increased congestion, noise and visual impacts that accompany these projects.

In short, megaprojects usually work as symbols, visual symbols, and the complex process by which intended symbols become icons is not necessarily immediate and is highly contested, in other words, it is a political process, a power process - I am currently focusing on this idea of "contested iconicity" in a study of megaprojects in Abu-Dhabi, Hong Kong and Sydney.

In addition to helping cities globalize, iconic buildings, most of which seem to win over the hearts and minds of an initially skeptic public, are a powerful tool in transmitting the consumerist values and practices that sustain capitalist globalization.

If iconicity is a visual manifestation of power, then it follows that the drivers of iconic megaprojects will be looking for ways to establish both hegemony and legitimacy, and, in fact, iconicity frequently works as a maneouver of distraction at the local level, be- 
cause UMPs are used to establish an "hegemony of vision" which secures legitimacy for the new coalitions of public and private stakeholders who are behind UMPs through the spectacularization of both development perspectives and political programs. This takes away the focus from the substantive, onthe-ground transformations of the urban-regional socio-economic fabric, their drawbacks and their downsides.

The architecture of UMPs therefore needs to be positioned in two ways: on the one hand, it has to react to the urban surroundings and thus find a way to stand out against the existing buildings and placespecific styles and materials. on the other hand, the architects, planners and politicians responsible for the design of the umps have to find solutions to the problem of how to be visible in comparison with international role-models and similar projects in competing cities - of which there are plenty.

The iconicity debate relating to the architecture of UMPs is very much centered on the notions of placespecificity versus global uniformity and its links to the creation of urbanity. (I think it makes more sense to establish the dichotomy local-global in this context than it does when discussing scales of power.) But even here, which architectural elements are interpreted as place-specific or, alternatively, as presenting global standards, and how they are used to make a UMP visible, remains, ultimately, very much dependent on the local context, its planning histories and trajectories of path-dependency - and the political process, as mentioned earlier.

A discussion on centrality as power is incomplete without mentioning the idea of resistance. Like Foucault, Michel de Certeau sees resistance as an essential component of power relationships. But he does play and develop the conceptual space around resistance that Foucault had left open. He emphasizes those spaces of tension within the interstices of power where individuals are constantly reacting and resisting. De Certeau's merit is to creatively link a vast array of disperse empirical material in order to show that individuals ("the ordinary man, the murmuring voice of societies") indeed resist power in their everyday practices.

His goal is "to perceive and analyze the microbelike operations proliferating within technocratic structures and deflecting their functioning..." Power generates vast, silent multifarious practices of resistance on the part of individuals: if it is true that the grid of "discipline" is everywhere becoming clearer and more extensive, says De Certeau, "it is all the more urgent to discover how an entire society resists being reduced to it." De Certeau, let me say it, wants to observe the underside of the grid of power. It is not that he substantially modifies the content and the structure of what we saw in Foucault: he only changes the angle of visin [11].

Therefore, to strategies of power, De Certeau opposes tactics of resistance. These "ways of making do" constitute "the innumerable practices by means of which users reappropriate the space organized by techniques of sociocultural production." They are "tactical," not "strategic," because they lack "a proper place," says De Certeau. In other words, consumers or "do-makers" resist in the space of the other, "within enemy territory" [12].

From this discussion on centrality as visual power and iconicity follows that iconic urban megaprojects may be qualitatively different regarding outcomes and impacts from non-iconic urban megaprojects, but are they? And if they are, does this warrant a systematic comparison of the first group with the second group? Would this be the most meaningful comparative effort? the way to do this would be using reference class forecasting, which achieves accuracy in projections by basing them on actual performance in a reference class of comparable actions and thereby bypassing both optimism bias and strategic misrepresentation.

\subsection{Borders and Citadels}

Why is a reflection on "borders" important to understand megaprojects? it is clear that producing boundaries is a political strategy, an often an aggressive one, a strategy of power to control, to obtain legitimacy and neutralize or eliminate resistance, to create hegemony in space. Producing boundaries means establishing a turf and defending it, and this strategy clearly has to do with the usually controversial character of large urban projects in the fabric of the city.

The convulsion they usually produce in the habitual workings of the city, their drawbacks and downsides, their negative impacts, their effects on displacement, on gentrification, their negative environmental effects, the burdens they cause in public finances - all of this needs to be contained or assuaged in advance through a careful plan that includes not only the visual power of icons and the effective man- 
agement of space (abstract and concrete), but also the establishment of a strong sense of demarcation and identity that makes their success more likely, as seen from the perspective of the interests of the growth machine.

Through bordering, megaprojects may produce and enhance urban fragmentation. this is clearly so in the case of gated megaprojects, which are instances of socio-spatial segregation, as in citadels, enclaves or ghettos, but it is also present in other megaprojects that aim at becoming fabricated and yet "open" spaces in the city. You may remember the debate by political economists on the "dual city" (Castells/Mollenkopf) and later the idea of a "quartered city" of Peter Marcuse, both echoing the analysis on fragmented societies by Enzo Mignione. These are dynamics of power produced by the workings of the global economy that parallel the spatial dynamics of power at work in producing borders during the planning and implementation of UMPs.

The idea of border is important because it leads us to reflect on the idea of "inclusiveness" as we study urban megaprojects. Here I would like to pose three questions:

A. in what ways do boundary-production processes obey a hegemonic logic of vision? and whose aim is to foster the global visibility of projects and the cities where they are built? how can we characterize the relationship between the two, between borders and visibility?

B. through the power strategy of border production, in what respects do umps become "citadels" "enclaves" and "ghettos"? - while the ghetto " stems from a high constraint, the enclave accounts for a more intentional form of segregation and the citadel refers to a deliberate attempt to exclude undesirable populations. these power strategies highlight the negative consequences of bordering for city life.

C. is participatory planning in urban megaprojects a good answer, and a good political strategy, to overcome the stifling of public spaces and the consequent transformation of the meaning of the public that has been taking place under neoliberalism, at a time when the ongoing crisis of liberal democracy seems to require new alternatives to the urban question?

The concept of space is paramount in de Certeau's
The Practice of Everyday Life. Essentially, De Certeau sees spaces as "practiced places." The walker in the city, for example, continually invents spaces by means of practicing the places in the built urban environment. Walking defines spaces of enunciation. Similarly, geometry opposes itself to experienced anthropology, and so do maps (reifications, abstractions of the rich diversity of itineraries that can be practiced by individuals) in relation to tours. Power strategically establishes a place, an order, a particular distribution of stratified elements available for analysis, whereas resistance tactically articulates variations within such an order, and so practices spaces. Practices of resistance become, then, "spatial stories," and through them there occurs "a constant transformation of places into spaces and of spaces into places." Spaces, thus, are thought of as open to human creativity and action. De Certeau believes that spaces can be more easily liberated than Foucault imagines, because individual practices "spatialize" rather than localize in repressive grids of social control. Space, therefore, is not simply a metaphor for a site or container of power [13].

Resisting means then marking out boundaries, for the symbolic creation and recreation of spaces is an act of partitioning and differentiating. In this sense, it also constitutes and act of foundation, "of creation of a field that authorizes dangerous and contingent social action" in a "fragmented," miniaturized," and "polyvalent" form. But resisting (spatial stories, practices, operations) also means transcending frontiers and crossing bridges. By privileging a "logic of ambiguity," the spatial stories of resistance represent "a departure, an attack on a state, the ambition of a conquering power, or the flight of an exile; in any case, the "betrayal' of an order," the "tour over the state," narrativity "in its most delinquent form" [14].

De Certeau notes that modern society embraces a much broader number of "procedures" of power (and of resistance) than those uncovered by Foucault, who focused only on a particular set of disciplines: those privileged by his own research program and historical analysis. Foucault was led to "cut out," to "make a selection from the ensemble of procedures that form the fabric of social activity in the eighteenth and nineteenth centuries." For De Certeau, "it remains to be asked how we should consider other, equally infinitesimal, procedures, which have not been 'privileged' by history but are nevertheless active in innumerable ways in the openings of established technological 
networks," and which have "vampirized" those that took place earlier on in history [15].

De Certeau (Part II) also criticizes Foucault's (and Bourdieu's) theoretical reductionism. In addition to "cutting out," Foucault was also forced to "turn over," to cluster and contrast the variety of procedures of power in two distinct historical periods around two different "regimes of truth," or "discursive regimes." These frameworks provide power strategies with their own distinctive objects of inquiry, procedures of imposition, and established sanctions. Power strategies have "their proper place," De Certeau would say. Incidentally, this is the reason why Foucault asserts that power reorganizes and appropriates space in a single, hegemonic (panoptic) way [16].

On the contrary, for De Certeau any temptation to reduce the infinite number of practices of resistance should be seen as a new systemic imposition of scientific rationality, as a new ideology. Unlike Foucault's regimes of truth and the category power/knowledge, De Certeau proposes the concept of "narrative." Instead of Bourdieu's logic of practice, he suggests that the radical singularity of practices - each of which operates according to a type of situation - can only be accurately approached through narrative. Practices are arts," and thus "a kind of knowledge that operates outside the enlightened discourse which they lack." One has to consider "what these techniques do. No need to interpret. It suffices to describe" [17].

De Certeau conceives narrative in a quite broad way (chapter 5) as creations of spaces (as opposed to established places), as description (as opposed to theorization), as an art (as opposed to discourse), and as a private knowledge that remains "on the margins...of scientific or cultural orthopraxis." It is "the status of a know-how without discourse." Not only all manifestations of popular culture (ordinary language, tales, games, legends), but also any kind of "spatial practice" (walking, incarceration, railway navigation), and also reading and believing constitute objects for narrativity. Narrating represents an avoidance of totalizations and a foundation of spaces (which, as we have seen, challenge the unifying thrust of places). Indeed, "deprived of narrations...the group or the individual regresses toward the disquieting, fatalistic experience of a formless, indistinct, and nocturnal totality" [18].

\subsection{Power As Growth Machines}

We need to examine, even if briefly, the idea of growth and the ideology of growth. We need a careful examination of the role of urban elites - politicians and officials, political opportunity structures, and state actors - in explaining the genesis, development, and impact of pro-growth coalitions. I mention "growth" because this is the main explicitly stated objective of UMPs, practically everywhere, through the politics and strategic plans for regeneration and revitalization. There is a surprising degree of uniformity in policy objectives. The specific outcomes and impacts vary wildly, but we know that in most cases UMPs do not live up to their promises - we have cost and time overruns, benefit shortfalls, excessive burdens in public finances, problems in excessive rise in property values, gentrification of many kinds, including tourist gentrification, displacements (of people, spaces, nature and of local cultures).

When talking about "growth" we have a very handy concept to operationalize "growth" in terms of power - the "growth machine" concept. This is a concept with a distinguished history (Logan and Molotch), and one that approaches power in terms of social action, confronting and overcoming the excessively structuralist accounts of the urban question developed in the early 1970s [19]. Obviously there is not only social action when we analyze power and politics, but a duality of agency and structure, or what Anthony Giddens calls "structuration" - it is both individuals or social forces that shape our social reality, and by the way, social forces are real and do have causal power as much as physical forces do.

How to apply this idea to UMP research? We need to make use of narratives of path dependency, historical accounts, scaling and policy feedback to argue persuasively that past events, structures, and actions, as well as key decisions and conflicts, have the potential to alter or narrow the field of action of planners, designers, engineers, financiers, politicians, bureaucrats, the media, the citizens, in sum, the field of action of growth coalitions and policy strategies. And how to portray the roles of these drivers as being influenced by both agency and structure in the design, the planning, the management, the governance and the outcomes and impacts of umps? Not an easy question when we craft our research designs and when we later build the narrative on research results. 


\section{On the Urban Imagination}

In order to lay the groundwork for transdisciplinary urbanism, let me invoke a certain urban imagination which has to do with the practice of everyday life in the city, a practice that UMPs usually take by assault. we know that urban megaprojects are neutralized spaces that wall off the differences between people, that reflect our fear of exposure to the other. they are spaces which remove the threat of social contact: street walls faced in sheets of plate glass, highways that cut off neighborhoods and people from the rest of the city.

The negative experience of walls, borders, isolation and detachment - all of this contrary to the ideal of inclusiveness - may be rooted in the centuries old tendency to privilege the inner space of consciousness over the external space of the physical world, as richard sennett has argued. The origin of the blandness and neutrality of urban space, which we see exacerbated in urban megaprojects, can be traced back in history to the belief that the outside world of things is not as deserving as the inner world of the mind. and, very interestingly, this is the equivalent to privileging the perspective of epistemology over ontology, over the conscience of the eye and over the value of observations that we see in certain approaches to the "planetary urbanization" question. (note: i did not say empiricism, but rather observations.)

Megaprojects often minimize the positive value of mingling, of encountering something alien, unsettling and potentially enlightening in their own streets. the skyscraper and other urban megaprojects afford the experience of isolation: "the view through the plate glass window reduces street life to the status of a framed picture, unthreatening yet bogus - it is a sight... routinely insulated from sound, and touch and other human beings."

The issue then is how to revive the reality of the outside both as a dimension of human experience and as a research strategy. In the words of sociologist Richard Sennett:

"Like the 19th-century romantics, we discover that unity can bring isolation and withdrawal. In the end, sympathy is outlawed by wholeness. This insufficiency causes us to send out shoots toward others whom we need to trust, a trust whose signs are only to be found in shared moments and shared spaces. Urbanites - including researchers - need to develop a creative art of exposure. We need to expose ourselves to the diversity of city life and develop an empathetic eye that perceives differences, affirms and even celebrates them. Uncertainty, exposure, discovery result from a focus on the observation of concrete materials, not from the workings of the mind in isolation. This turning outward involves a renunciation of certain impulses to wholeness and completion in oneself. This is what the city needs to invite ethical vision" [20].

In the spirit of Richard's reflections the question ought to be - which megaprojects should have never been planned, designed, built, and which of them can still be defeated? This is obviously a civil society and democracy question, that is, a political question, but it can also be interpreted in strict technical terms as a performance evaluation question. In both cases, we contend that a transdisciplinary approach offers the most promising way to answer the question.

\section{Transurbanism and the Outside}

Sennett reminds us that we need to expose ourselves to the diversity of city life and develop an empathetic eye that perceives differences, affirms and even celebrates them. Uncertainty, exposure, discovery result from a focus on the observation of concrete materials, not from the workings of the mind in isolation. Transdisciplinary urbanism is a proposal to focus on the reality of the outside both as a dimension of human experience and as a research strategy. This entails an ethical stand, that of noblesse d'espirit, that ought to drive our quest for knowledge and social change. The "reality of the outside" is not only the physical reality that embraces the city outside of urban megaprojects, but also the phenomenological reality of the knowing subject "being-in-the-world," and political reality outside of the priorities of elites that are never going to make the necessary efforts to improve society. The urbanism of the outside is a transdisciplinary endeavor enacted from multiple agencies, from the bottom up, from the margins to the center.

In recent years, citizen participation in urban planning processes has become both a demand and a re- 
ality. As the result of major economic crises around the world and growing awareness of the exploitation of the environment and climate change, disenchanted citizens have demanded to be more hands-on in deciding about and inuencing their living environments, while public authorities retaliate by drawing lines of jurisdiction. In the eld of architecture and urbanism, some have advocated for a radical change aimed at expanding design practice into a socially and politically relevant eld. Here the idea, put forward by Rizzo and Galanakis, is to develop a new urbanism education curriculum to include public-service practice, similar to the long-established curricula in law and medicine.

At the same time, in the heterogeneous eld of urban studies, many are starting to side with urban activists and artists to bring about the change that mainstream planning has failed to deliver. According to this view, public space has become the focus and location to organize artistic and cultural interventions that aim at questioning, amongst others, the current land use program, social and political injustice, and ultra-liberal privatizations of public commons. However, many questions arise about the use of art in urban studies, such as, how the extensive critical theoretical work on urban space and processes of urbanization of recent decades may further inform artistic practice, performance and intervention.

Within urbanism, several attempts have been made towards less reductive approaches to space and design; approaches that no longer choose between theory and practice as the ideal locus for critique, but, instead, allow critique to be processed in ways that are more complex and more entangled; approaches that advocate hybrid modes of inquiry. One can think of the hybridisation of nature and technology, engineering and the social, facts and values, human and non-human, and the explicit attention to agency in Science and Technology Studies (STS) and Actor-Network-Theory (ANT). Such approaches have in common their suggestion to approach urban issues not according to predefined ideologies or (critical) theories but to study them as a problem of the outside - as situated, complex gatherings of all sorts of agencies, where the notion of context and transdisciplinarity are essential.

We believe with Doucet and Janssens that, when countering the idea of design practice as a mere applied theory, and instead considering the archi- tectural and urban question as hybrids, complex gatherings, and "messy undertakings", we should nevertheless not content ourselves with doing this alone. Both accountability and designerly, complex ways of understanding urbanism's agency in the world should be confronted with the fact that, no matter how well we develop tools to deal with it, and thus account (take responsibility) for such complex engagements, we will always be facing the contingency of design, a "leap in the dark". Namely, we can never entirely predict what the design itself will result in and what effect a design outcome will have, which unexpected agencies may enter, and what surprises we can enjoy [21].

Urban designers, despite insecurities about the effects of their actions, nevertheless act in a concerned manner and be held responsible for their actions. They ought to engage with the world in an irreductive, complex, and problematising manner rather than in a reductive fashion. In other words, they need to allow for surprises and with it "other possibilities" and, thus, "hope" as necessary elements for the enhancing of urbanisms projective capacity. No matter how well our design methods may become in order to deal with the complexity of the world, as soon as it starts to aim to control that complexity and contingency again, chances for the unexpected, for events to emerge, are constrained, and with it, any possibility for change. The answer to these challenges may be a transdisciplinary approach to urbanism that takes into account both the discovery (knowledge) dimension and the design (creation) dimension [22].

The common denominator of all approaches is an attempt to reconcile, exact sciences, social sciences, design and philosophy and advocate for a new transdisciplinary paradigm. The transdisciplinary framework envisioned here is similar to that suggested by Gibbons et al. in their "Mode 2" of knowledge production, i.e. a dynamic framework in which multiple players combine empirical and theoretical knowledge to solve applied problems: a combination of knowledge and design, as discussed by Rizzo and Galanakis [23]. Dosse notes that the social sciences are witnessing "a genuine transformation" where terms such as chaos, process, meaning, complexity, and self-organization are slowly replacing the classic concepts of structure, static, combinatory, and universal. In this new framework, Dosse claims that the task of the transdisciplinary-scholar is to clarify, 
rather than dissect, the "judgments of fact" from the "judgments of value" [24].

Rizzo and Galanakis see Transdisciplinary Urbanism as a new, emerging methodological framework according to which social and action researchers from multiple fields, artists, animators, performers, activists, and local communities come together to study uncertainty, chance and open-endedness, and to transparently renegotiate power structures in urban space. Transdisciplinary Urbanism builds upon the social, philosophical and design aspects of Urbanism; it connects different theories and practices, and crosses disciplines in order to study and improve everyday life. The disciplinary crossovers entailed by such practices push inhabitants and professionals out from their comfort zones, encouraging co-operation and co-creation in non-predetermined ways.

Indeed, the exponential growth of both web-based interaction tools, physical sites where knowledge is created, and the recombination of extremely specialized elds in new knowledge entities have facilitated the emergence of a new form of knowledge production that Gibbons et al. have labeled "Mode 2," as mentioned earlier. As the opposite of "Mode 1", in which knowledge is eminently a contribution to compartmentalized disciplines, Mode 2 of knowledge production is characterized by transdisciplinarity, i.e. working within an evolving and dynamic framework in which empirical and theoretical knowledge are combined with design creativity and where multiple players (e.g., universities, research agencies, informal agencies, private rms, NGOs, etc.) contribute to the creation of such knowledge [25].

Transdisciplinarity can also be seen as an evolution of multi- and inter-disciplinarity. However, unlike these latter, transdisciplinarity does not seek to solve the paradoxes generated by the endless dissection of knowledge in smaller disciplinary units. Rather than aiming to the "unity of knowledge," by acknowledging the inherent complexity of the subject, transdisciplinarity directs to master the paradoxes. Building upon this, within Transdisciplinary Urbanism (TU), urban studies and design provide the theoretical and empirical foundation to conduct proactive (but not pre-determined) investigation of the effects of change in urban space becomes possible. TU researchers and the many actors working and living in the city work within the dynamic framework that is represented by contemporary polities, this latter shaped by unpredictable, constructive and destructive cycles.

\section{Concluding Remarks}

The process for transdisciplinary research in urbanism consists of three phases: problem identification, problem analysis, and bringing results to fruition. The designerly aspect has to do with the fact that these three stages do not necessarily occur in the given order, and with the fact that "bringing results to fruition" is not the same as problem-solving, and does not necessarily occur at the end of the research process. Rather, it takes place in the course of the research process in order to enable learning processes and is achieved in the form of a real-world experiment, which is, indeed, what an urban design can be considered to be.

In a context of hybrid knowledge among the exact sciences, the social sciences and philosophy, integration between theory and practice, ethical concerns, and the importance of experimental, designerly modes of inquiry become key to transdisciplinary urbanism. Transdisciplinary modes of knowledge production are characterized by hybridization, i.e. the loss of dependency from a specic disciplinary compartment. Transdisciplinary research includes at once what stands between disciplines, across disciplines and beyond any discipline. Transdisciplinarity is about the articulations, rather than the relations, between disciplines: the whole is more than the sum of its parts.

Because urbanism engages, both as a discipline and as a profession, with broader societal concerns (e.g. situated knowledge, participatory design, everyday practices), it therefore seems obvious that hybrid modes of inquiry are part of the knowledge landscape. In the context of this article we have used the broad understanding that, whereas interdisciplinary knowledge is located in scholarly environments, transdisciplinary knowledge production entails a fusion of academic and non-academic knowledge, theory and practice, discipline and profession.

Transdisciplinarity is a mode of inquiry, practice, and learning that places ethics, aesthetics, and creativity inside, not outside, of disciplinary and professional work. It brings new objects into view, places practices into new configurations, contextualizes and re-situates theory and learning, and incorporates social, political, and ethical questions once deemed beyond the proper sphere of research and educa- 
tion. The boundary work of transdisciplinarity is decidedly plural. It is generative, formative, and interrogative, catalyzing critique and transformations of our modes of inquiry, practice, and education.

Transdisciplinary urbanism ought to be inquirydriven rather than exclusively discipline-driven; meta-paradigmatic rather than intra-paradigmatic; informed by thinking that is complex, creative, contextualizing, and connective, following Edgar Morin [26]. Inquiry here is a process of creativity combining rigor and imagination. Transdisciplinarity is an attitude towards inquiry in urbanism, informed by certain epistemological presuppositions, and an effort to frame inquiry as a creative process that recognizes as central the subjectivity of the inquirer and challenges the underlying organization of knowledge. Problem-driven transdisciplinary urbanism investigates the interactions between the knowing subject and the object of knowledge. It encompasses discovery and creation, knowledge and design, science and creativity for a holistic interpretation of consciousness, space and social forces that includes theoretical, phenomenological and experimental concerns.

Funding: This research received no external funding.

Conflicts of Interest: The author declare no conflict of interest.

\section{References}

[1] Lin, H. W. and Abraham Loeb (2015). "A Unifying Theory for Scaling Laws of Human Populations." Institute for Theory \& Computation, Harvard-Smithsonian Center for Astrophysics, pp. 6-12; Gabaix, Xavier (1999) "Zipf 's Law for Cities: An Explanation." The Quarterly Journal of Economics. 114 (3): 739-67. This section follows Anthony Townsend (2015) "Making Sense of the New Urban Science," New York University report http://www.citiesofdata.org/wpcontent/uploads/2015/04/Making-Sense-of-theNew-Science-of-Cities-FINAL-2015.7.7.pdf

[2] Sobstyl, J.M., M.J. Abdolhesseini Qomi, R.J. - M Pellenq, and F-J Ulm (2014). "Urban Physics: City Texture Matters." MIT CSHub Research Brief. (Cambridge, Mass.: Massachusetts Institute of Technology), pp. 11-18. https://cshub.mit.edu/sites/default/files/documents/ October\%20brief\%20- \%20Urban\%20Physics\%20\%20v3.pdf.

[3] Edwards, Peter (2015). May 14. Videoconference interview by Anthony Townsend
[4] Ellard, Colin (2015). "Cities and Their Psychology: How Neuroscience Affects Urban Planning." The Guardian. http://www.theguardian.com/ cities/2014/feb/04/cities-psychology-neuroscienceurban-planning-study.

[5] Fainstein, S. (2008). Mega-projects in New York, London and Amsterdam. International Journal of Urban and Regional Research, 32(4), 768-783.

[6] Benevolo, L. (1999). The European City, Wiley Blackwell, p. 13. I follow the discussion by Florian Koch (2015) "The European City as a Transdisciplinary Concept. Contradictions and Potentials," Boletn de la Asociacin de Gegrafos Españoles, 67, pp. 457-463.

[7] Ibid. p. 223.

[8] Castells, M. (1979). The Urban Question. A Marxist Approach, Cambridge, MA: The MIT Press; Harvey, D. (2009) Social Justice and the City, Atlante: University of Georgia Press.

[9] Del Cerro Santamara, G. (ed.) (2013). Urban Megaprojects. A Worldwide View, Bingley, UK: Emerald Publishing.

[10] Lefebvre, Henri (1991). The Production of Space. Translated by Donald Nicholson-Smith. Oxford: Blackwell.

[11] De Certeau, M. (1984[1980]). The Practice of Everyday Life. Berkeley and Los Angeles: University of California Press, pp. xiv-xxiii.

[12] Ibid. pp. 29, 37.

[13] Ibid. pp. 115, 117, 119, 200.

[14] Ibid. pp 123-30.

[15] Ibid. pp. 47-62.

[16] Ibid. pp. 49, 65.

[17] Ibid. pp. 21, 59-67.

[18] Ibid. Chapter 5.

[19] Logan, J. And H. Molotch (1987). Urban Fortunes. The Political Economy of Place, Berkeley: University of California Press

[20] Sennett, Richard (1992). The Conscience of the Eye. The Design and Social Life of Cities, New York: W. W. Norton, p. 196.

[21] Doucet, I. and Nel Janssens (2011). Transdisciplinary Knowledge Production in Architecture and Urbanism. Towards Hybrids Modes of Inquiry, London: Springer, p. 156.

[22] Ibid. p. 178.

[23] Gibbons, M., Limoges, C., Nowotny, H., Schwartzman, S., Scott, P., \& Trow, M. (1994). The New Production of Knowledge: The Dynamics of Science 
and Research in Contemporary Societies, San Francisco: SAGE; I follow the discussion by Rizzo, A. and M. Galanakis (2015) "Transdisciplinary Urbanism: Three Experiences from Europe and Canada," Cities, 47, 3544.

[24] Dosse, F. (1999). Empire of Meaning. The Humanization of the Social Sciences, Minneapolis: University of Minnesota Press, p. 23.

[25] Gibbons et. al, op. cit. pp. 5-6.

[26] Morin, Edgar (2005). On Complexity. Cresskill, NJ: Hampton Press.

\section{About the Author}

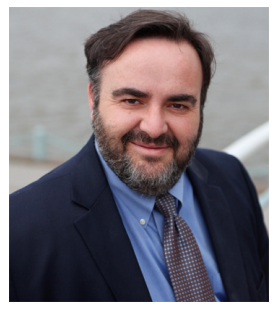

Gerardo del Cerro Santamaría, is a U.S. Fulbright Senior Specialist in Urban Planning from New York. He is an Invited Professor of Urbanism and Globalization at the School of Architecture and Planning, Shenyang Jianzhu University in China. He has been a Visiting Professor at MIT and a Visiting Scholar at Columbia University, as well as Research Professor of Planning and Megaprojects at The Cooper Union for the Advancement of Science and Art in Manhattan, where he also served as Senior Executive Director of Strategic Planning and Innovation. As of Fall 2018 he will be serving as a Senior Advisor to the Planning of the Jing Jin Ji Megalopolis in China. Del Cerro has published several books, journal articles and encyclopedia entries. He is the author of Bilbao. Basque Pathways to Globalization (2007); editor of and contributor to Urban Megaprojects. A Worldwide View (2013); and author of "Megaprojects in Global Context" in The Oxford Handbook of Megaproject Management (2017). He has a background in Science, Music Theory, Logic and Philosophy of Science and holds Ph.D.'s from the New School for Social Research in New York (Political Economy) and the Universidad Autónoma de Madrid, Spain (Economic Sociology). 